\title{
Corrosion Behavior of Low Carbon Steel Pipe in Condensate Environment
}

\author{
Ahmad Royani*, Siska Prifiharni, Gadang Priyotomo and Sundjono \\ Research Center for Metallurgy and Materials, National Research and Innovation Agency, \\ Puspiptek 470, South Tangerang, Banten, Indonesia
}

("Corresponding author's e-mail: ahmad.royani@brin.go.id)

Received: 4 September 2020, Revised: 20 May 2021, Accepted: 4 June 2021

\begin{abstract}
Low carbon steel pipe is widely used in various pipeline applications because it has good mechanical properties. The application of low carbon steel developed generally does not involve corrosion resistance. To find out the behavior of low carbon steel pipe in condensate fluids, the immersion test was carried out. The method for the immersion test is the planned-interval test. The corrosion rate of this steel was determined by weight loss, whereas the corrosivity of the condensate fluids was measured by a multimeter Hach HQ40d. The morphology of corrosion products is characterized by using scanning electron microscopy (SEM), energy dispersive spectrometry (EDS), and $\mathrm{x}$-ray diffraction (XRD). The result of immersion of low carbon steel pipe in the condensate fluids shows that the liquid corrosivity and corrodibility of low carbon steel pipe tend to decreases with the length of exposure time. The decrease of metal corrodibility is identical to the lower corrosion rate at a longer exposure time due to the layer a corrosion product formed. The corrosion products during immersion tests are uniform with iron oxide in the form of $\mathrm{FeO}(\mathrm{OH})$ and $\mathrm{Fe}_{2} \mathrm{O}_{3} \cdot \mathrm{H}_{2} \mathrm{O}$.
\end{abstract}

Keywords: Condensate, Corrosion, Immersion, Steel pipe, Weight loss

\section{Introduction}

The main problems in condensate pipeline systems in geothermal power plants include corrosion, deposits, and slime. Corrosion can shorten the service life of material pipelines because it results in reduced operating efficiency, leakage, and pollution [1]. Deposits and slime in addition to reducing heat efficiency in heat exchangers and pipeline systems also cause local corrosion that is corrosion under the deposit due to differences in oxygen concentration [2]. These problems occur in very complex and many contributing factors.

The source of raw water in condensate pipeline systems can come from groundwater, lakes, rivers, and seawater [3]. In general, raw water contains suspended solids and dissolved solids which can cause corrosion or deposits.

The water circulating system in the cooling water consists of a once-through system, a closed system, and an open system [4]. The once-through system delivers water to the cooling unit and discharges it back to the water source. In a closed system, water loss is so low that there is no addition of water during the operation. Meanwhile, in an open system, a loss of water so it must have a supply of water added as a substitute [5]. Thus, in closed recirculation minerals accumulate much less than in open systems where there is an increase in the amount of water from make-up water. Cooling water in open and 1-cycle recirculation systems is usually contaminated with a number of solutes, suspended solids, and microorganisms. Therefore, the formation of deposits, the occurrence of corrosion, and the formation of slime in open and 1-turn recirculation systems are generally more significant than in closed systems [4].

Most of the materials in condensate pipeline and heat exchanger systems contain components made from copper and steel alloys. Carbon steel is used mostly in cooling water lines and heat exchanger units in closed and open recirculating systems [6]. Carbon steel is used in parts of heat exchanger units and cooling towers while stainless steel is found in piping systems [7]. Therefore, it is important to understand the corrosion behavior of these materials due to contact with fluids in the cooling system. 
One of the factors that influence the formation of corrosion and deposits (scale) in the cooling system is the fluid content itself. Critical parameters for fluids include temperature [8], velocity [9], conductivity, total dissolved solids (TDS), hardness, $\mathrm{pH}$, alkalinity, and saturation index [10].

In this study, the low carbon steel in an immersion test was carried out by using condensate fluids according to ASTM G-31 standards [11]. The aim is to determine the corrosion behavior of low carbon steel pipes in a condensate environment. The object of study is the corrosivity of condensate fluids and the corrosion rate of these steel with the exposure time. The expectation from these results is data to be basic in the application of carbon steel in the corrosive environment, especially in the condensate environment.

\section{Materials and methods}

The specimens of steel pipe and condensate fluids from a geothermal power plant were used in the study. The chemical composition of steel pipe specimen in Table $\mathbf{1}$ with microstructure as in Figure $\mathbf{1}$. While for the water quality parameters of condensate fluids are presented in Table 2.

Table 1 The chemical composition of specimen steel pipe.

\begin{tabular}{ccc}
\hline \multirow{2}{*}{$\begin{array}{c}\text { Element } \\
\text { (\% wt. })\end{array}$} & \multicolumn{2}{c}{ Name of Material } \\
\cline { 2 - 3 } Fe & Specimen pipe & API 5L Gr B \\
$\mathrm{C}$ & Balance & Balance \\
$\mathrm{Mn}$ & 0.0802 & $0.22 \max$ \\
$\mathrm{Si}$ & 1.1086 & 1.28 \\
$\mathrm{~S}$ & 0.2572 & 0.45 \\
$\mathrm{P}$ & 0.0035 & 0.03 \\
\hline
\end{tabular}

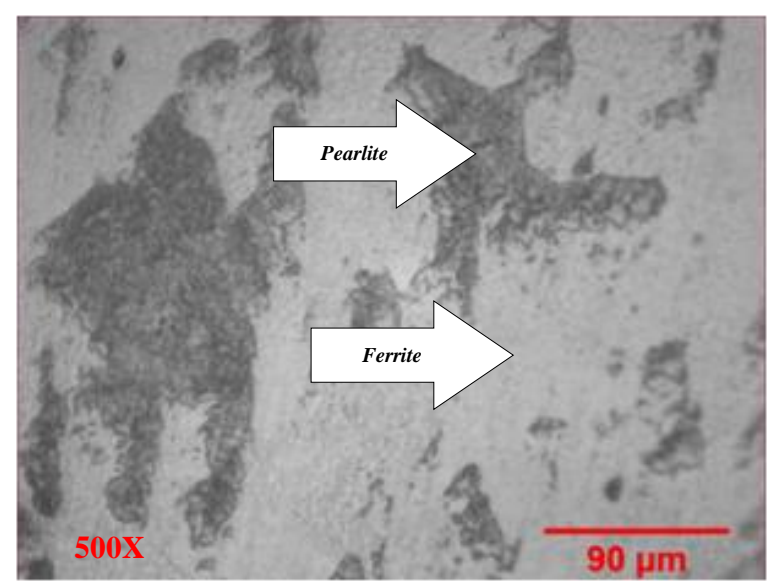

Figure 1 The microstructure of low carbon steel pipe.

Table 2 The chemical composition of the condensate fluids.

\begin{tabular}{ccc}
\hline Parameter & Unit & Composition \\
\hline Calcium Hardness & $\mathrm{ppm}$ & 1 \\
Total Alkalinity & $\mathrm{ppm}$ & 3.7 \\
$\mathrm{pH}$ & - & 5.63 \\
Temp. & ${ }^{\circ}$ & 28 \\
Salinity & $\mathrm{ppt}$ & 0.12 \\
Conductivity & $\mu \mathrm{s} / \mathrm{cm}$ & 254 \\
Dissolved solids & $\mathrm{ppm}$ & 121 \\
\hline
\end{tabular}


The steel pipe is cut with dimensions of $70 \times 20 \times 2 \mathrm{~mm}^{3}$, then coded, and then perforated on the top end. Before the immersion test, the surface of the specimen is cleaned according to ASTM G1 standard practice for preparing, cleaning, and evaluating corrosion test specimens [12]. After surface cleaning, the specimens were weighed using analytical scales and then stored in a desiccator.

The immersion test was carried out by the put of the specimen into a reactor glass at a certain time in the water batch. The panel device is turned on by turning the power switch to the ON position. Adjust the water level and solution temperature, after the desired temperature has been reached, the quality parameters of the solution test are measured with a sensor probe (Multi-Meter HQ40d). If conditions have been reached, the specimen is put into the solution test by hanging the specimen in the holder using a string. Then, the reactor glass is closed and left for a certain exposure time. The method used in this immersion test is the planned interval test method. The design of the interval test is illustrated in Table 3.

Table 3 The design of the planned-interval test.

\begin{tabular}{ccccc}
\hline \multirow{2}{*}{ No } & Code & \multicolumn{2}{c}{ Period (weekly) } & Exposure time (days) \\
\cline { 3 - 4 } & & $\begin{array}{c}\text { Initial } \\
\text { exposure }\end{array}$ & Finished exposure & 7 \\
\hline 1 & A1 & 0 & 1 & 21 \\
2 & A3 & 0 & 3 & 28 \\
3 & A4 & 0 & 4 & 7 \\
4 & B & 3 & 4 &
\end{tabular}

After the immersion test, the specimen is cleaned according to the procedure ASTM G1. The method for determining the corrosion rate based on weight loss follows the following equation;

Corr. Rate $=K\left(\frac{W}{D A T}\right)$

where, $K$ : constants; $W$ : lost weight (grams); $D$ : steel density $\left(\mathrm{g} / \mathrm{cm}^{3}\right) ; A$ : area $\left(\mathrm{cm}^{2}\right)$; and $T$ : exposure time (hours).

Measurement of the quality of the condensate fluids is done by using a portable multimeter Hach (HQ40d). The parameters measured include solution temperature, salinity, the content of dissolved oxygen (DO), conductivity, TDS (total dissolved solids), and $\mathrm{pH}$. The measurement of the quality of the test media is carried out periodically.

The morphology of the corrosion products from the surface specimen was observed using scanning electron microscopy (JEOL JSM-6390A) and energy dispersive spectrometry (EDS). The corrosion product compounds were analyzed using x-ray diffraction (Shimadzu XRD 7000).

\section{Results and discussion}

Based on the results of the chemical composition, the pipe steel specimen is identical to API 5L Grade B steel as in Table 1. The corrosion rate of the specimen was determined based on the weight loss method. The results of the corrosion rate in mpy (milli-inch per year) for low carbon steel pipe versus exposure time are presented in Figure 2. From data of the corrosion rate in Figure 2, it's can be seen that the corrosion rate in the first week (A1) is higher than the last week (B). These results indicate that the liquid corrosivity of the condensate fluids decreases. The result of the subtraction of the corrosion rate in the fourth (A4) and third (A3) weeks is lower than the corrosion rate in the last week (B), indicating that the corrodibility of the specimen tends to decrease. The declined corrodibility of metals is due to decreased contact between the metal surface and the condensate fluids after the corrosion product is formed. The presence of a corrosion product layer on the metal surface can inhibit contact metal with a solution so that the corrosion rate decreases with the time of exposure [13]. 


\section{Corr. Rate of Low Carbon Steel Pipe}

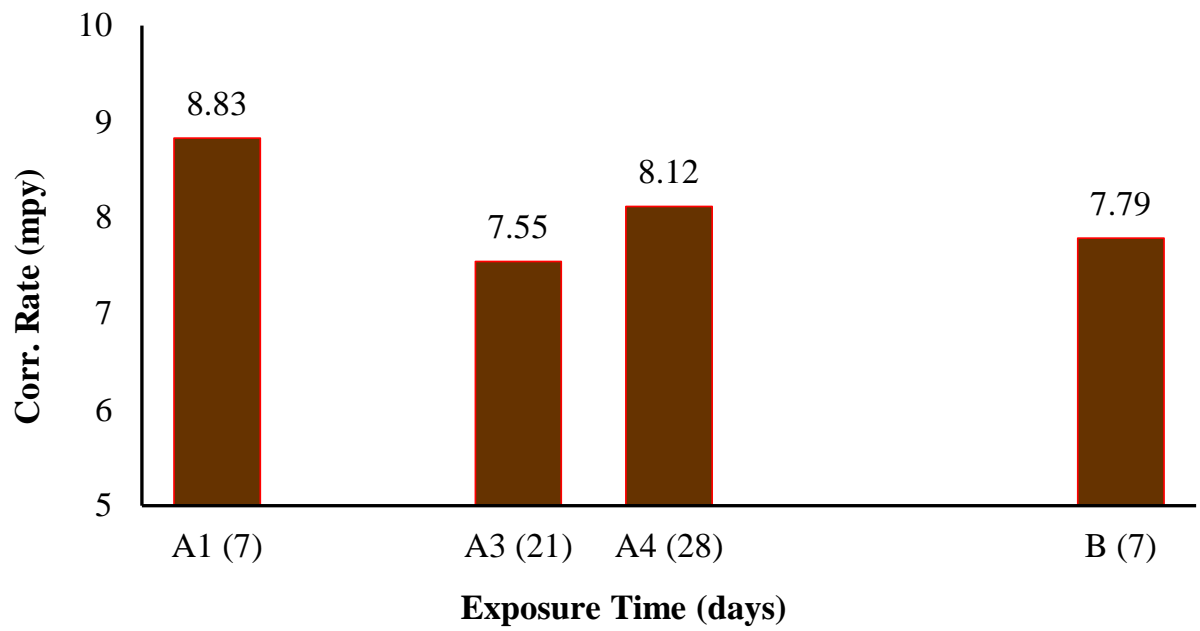

Figure 2 Corrosion rate versus exposure time.

Based on the corrosion rate obtained from the immersion test, the corrosion of the specimen in this study was included in the poor category as the classification in Table 4. During the immersion of the specimen, many possibilities occur in both the specimen and the solution test. Changes in conditions during the immersion process with the planned-interval test are described in Table 5. The corrosion rate from Figure 2, it to tend category no. 5 in Table 5, with decreased condensate fluid parameters.

Table 4 The category of corrosion rate for steel in the open recirculating system [10].

\begin{tabular}{cc}
\hline Corrosion rate (mpy) & Category \\
\hline$\leq 1$ & Excellent \\
$1-3$ & Very good \\
$3-5$ & Good \\
$5-8$ & Moderate \\
$8-10$ & Poor \\
$>10$ & Very poor \\
\hline
\end{tabular}

Table 5 The criteria of the planned-interval test [14].

\begin{tabular}{cccc}
\hline No & Liquid corrosiveness & Metal Corrodibility & Criteria \\
\hline 1 & Unchanged & Unchanged & $\mathrm{A} 1=\mathrm{A} 2=\mathrm{B}$ \\
2 & Unchanged & Decreased & $\mathrm{A} 2<\mathrm{B}=\mathrm{A} 1$ \\
3 & Unchanged & Increased & $\mathrm{A} 1=\mathrm{B}<\mathrm{A} 2$ \\
4 & Decreased & Unchanged & $\mathrm{A} 2=\mathrm{B}<\mathrm{A} 1$ \\
5 & Decreased & Decreased & $\mathrm{A} 2<\mathrm{B}<\mathrm{A} 1$ \\
6 & Decreased & Increased & $\mathrm{A} 1>\mathrm{B}<\mathrm{A} 2$ \\
7 & Increased & Unchanged & $\mathrm{A} 1<\mathrm{A} 2=\mathrm{B}$ \\
8 & Increased & Decreased & $\mathrm{A} 1<\mathrm{B}>\mathrm{A} 2$ \\
9 & Increased & Increased & $\mathrm{A} 1<\mathrm{B}<\mathrm{A} 2$ \\
\hline
\end{tabular}


The corrosion rate of steel depends on several parameters such as the chemical composition of the steel [15], the surface roughness of the steel [16], and the environment [17]. Water environmental parameters include temperature, salinity, the content of dissolved oxygen (DO), conductivity, TDS (total dissolved solids), and $\mathrm{pH}[5]$.

One of the water quality parameters of the condensate fluid that affects the liquid corrosivity is the temperature itself. In general, the temperature can increase the corrosion rate exponentially with an increased temperature of $10{ }^{\circ} \mathrm{C}$ [18]. The corrosion rate is tripled or quadrupled when the temperature of the water rises [19]. The results of the measurement of the condensate temperature are presented in Figure 3. In this study, the temperature parameters of the condensate media were kept constant at $50{ }^{\circ} \mathrm{C}$ and did not experience a significant change. Therefore, the temperature change of the condensate is maintained as much as possible and the effect of temperature on the corrosion rate is not significant in this study.

\section{Condensate Quality Parameters}

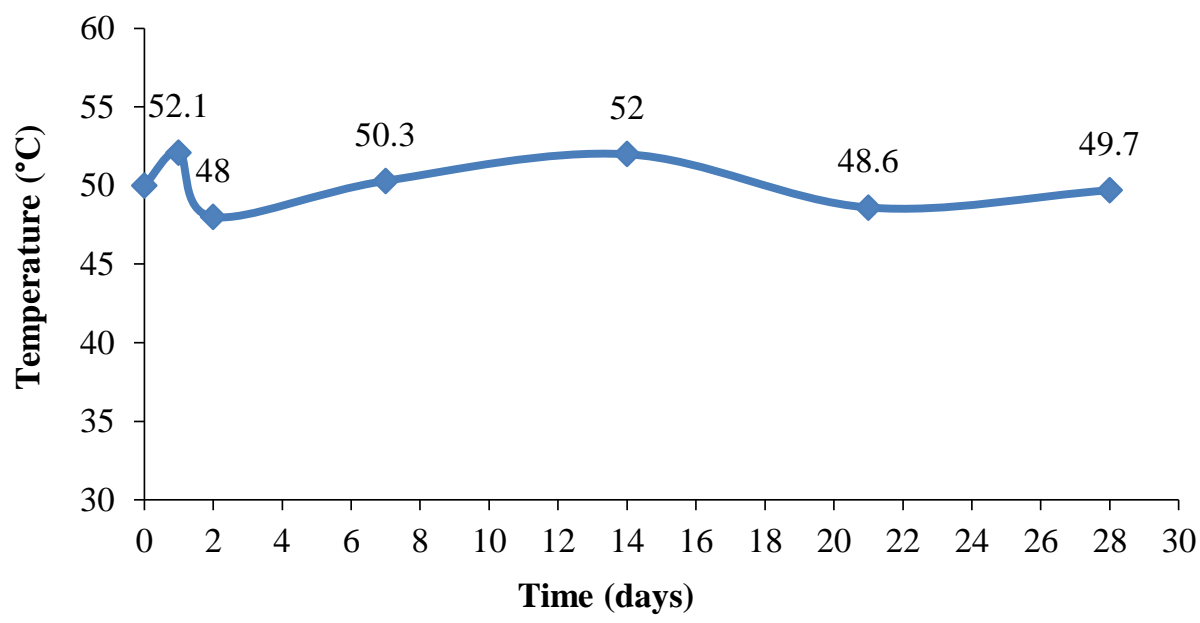

Figure 3 The result of solution temperature versus exposure time.

The liquid corrosivity is not only influenced by temperature but also influenced by many parameters. One of those parameters is chloride content. The chloride content in water is defined as salinity [3]. Therefore, salinity is predicted by determining the concentration of $\mathrm{Cl}^{-}$ions in water. The empirical correlation between salinity and $\mathrm{Cl}^{-}$ion content is formulated in equation [4];

$\mathrm{S}=1.80655 \times\left[\mathrm{Cl}^{-}\right]$

The salinity measurement results from the immersion test are presented in Figure 4. The salinity obtained is relatively the same and the value is very small, between $0.10 \mathrm{ppt}$ and $0.09 \mathrm{ppt}$. These results indicate that the condensate fluid is included in the category of freshwater because the content of chloride ions is below 1,000 ppm [4].

The liquid corrosivity of natural water increases proportionally if the value of salinity increases. If salinity exceeds $3 \%$, water corrosivity will decrease [18]. Otherwise, the higher the salinity, the lower the oxygen solubility [20]. Thus, with salinity above $3 \%$, the rate of corrosion in the water decreases. Likewise, if salinity is very small, the effect is very small on the rate of corrosion. 


\section{Condensate Quality Parameters}

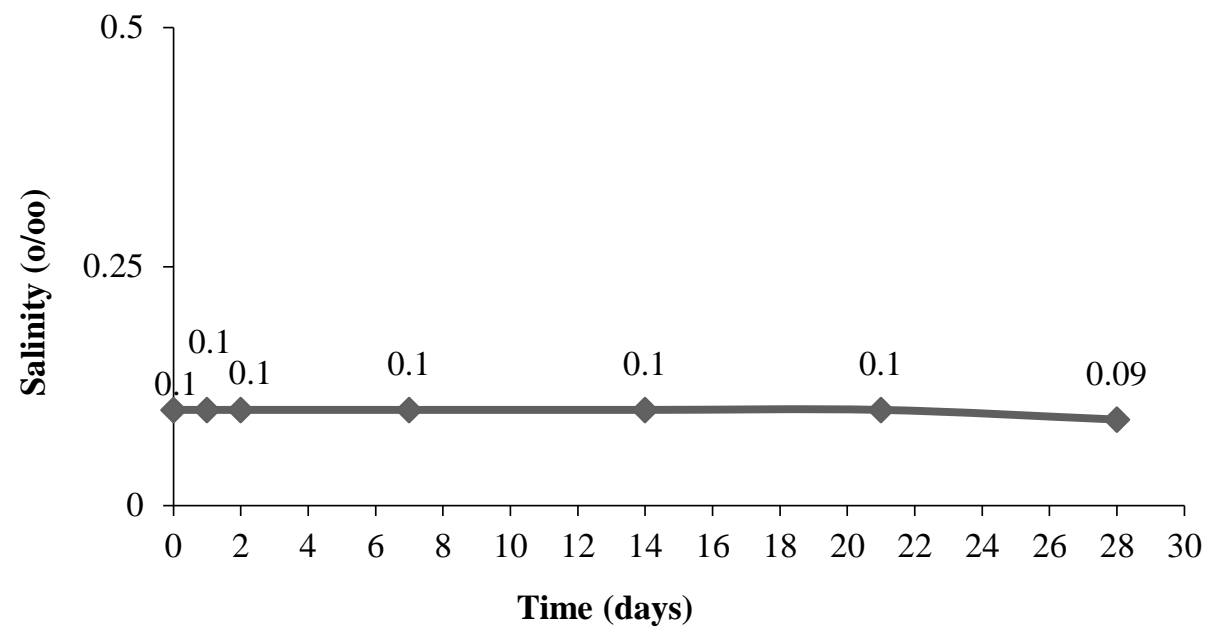

Figure 4 The result of salinity versus exposure time.

Another parameter of water quality that affects the corrosion rate in the condensate environment is the content of dissolved gas. Dissolved gas that affects the corrosivity of the solution in the corrosion aspect is oxygen and carbon dioxide [21]. The solubility of oxygen and carbon dioxide decreases with increasing temperature and salinity [22]. Carbon dioxide gas can affect the $\mathrm{pH}$ of the solution, the presence of $\mathrm{CO}_{2}$ gas makes the solution more acidic [23]. Oxygen acts as a depolarizer in the cathode and increases the corrosion process [14]. The results of dissolved oxygen (DO) measurements versus immersion time are shown in Figure $\mathbf{5}$.

\section{Condensate Quality Parameters}

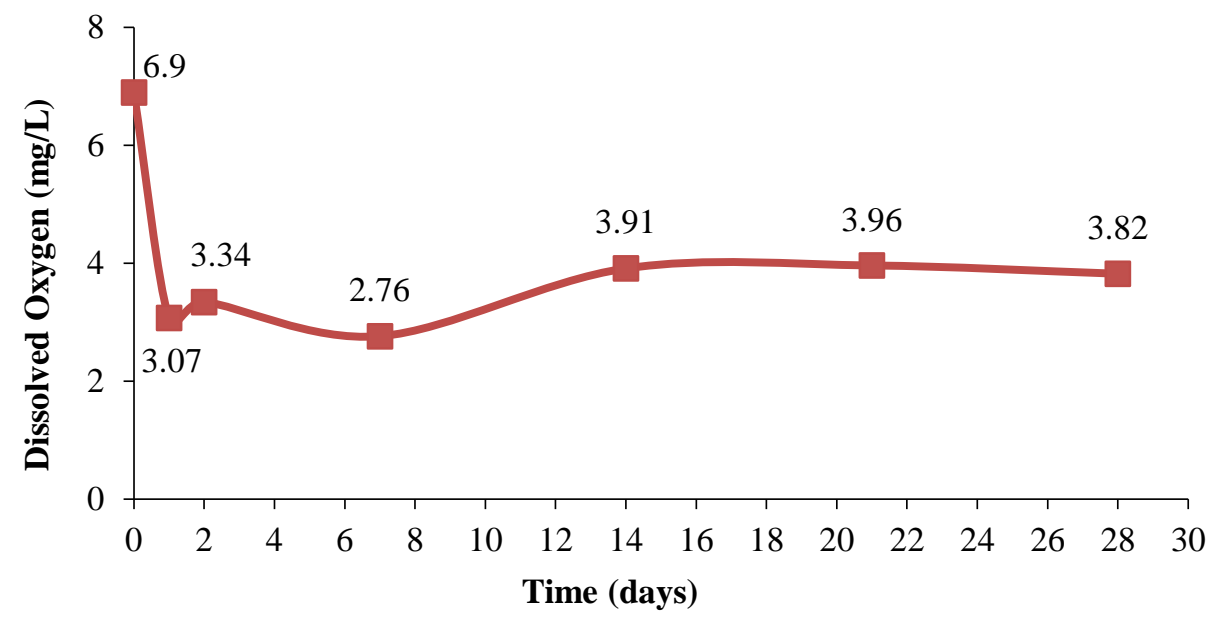

Figure 5 The result of dissolved oxygen versus exposure time.

Based on the data in Figure 5, it is clear that the effect of oxygen is seen on the corrosion rate. DO values decreased in the condensate fluids after the specimen is exposed. In the beginning, the initiation process of corrosion began to occur in the anodic region so that oxygen consumption in the cathodic region increased. As a result of this event, oxygen dissolved in condensate fluid decreased. The mechanism of chemical reactions occurring in a neutral solution by the following reaction equation [18]. 
At the anode area, iron $(\mathrm{Fe})$ dissolves to be iron ions $\left(\mathrm{Fe}^{2+}\right)$;

$\mathrm{Fe} \rightarrow \mathrm{Fe}^{2+}+2^{\mathrm{e}-}$

whereas at the cathode, the reduction reaction of dissolved oxygen occurs;

$\mathrm{H}_{2} \mathrm{O}+1 / 2 \mathrm{O}_{2}+2^{\mathrm{e}-} \rightarrow 2 \mathrm{OH}^{-}$

The above reactions occur simultaneously and a variety of further reactions occur in the solution. In the corrosion process, iron ions $\left(\mathrm{Fe}^{2+}\right)$ formed at the anode will oxidize to be iron oxide in the form of a thin layer on the metal surface and prevent further iron corrosion processes;

$\mathrm{Fe}^{2+}+2^{\mathrm{e}-}+1 / 2 \mathrm{O}_{2} \rightarrow \mathrm{FeO}$

Similarly, at the cathode, oxygen must reach the metal surface for the reaction (4) to occur. Hydroxyl ions $\left(\mathrm{OH}^{-}\right)$can also be absorbed on the surface to form a layer that oxygen absorption prevented. In this situation, the cathode polarization and the corrosion process run slowly. In a very rapid corrosion reaction, the barrier layer (protective) does not get formed, Fe ions react with hydroxyl ions;

$2 \mathrm{Fe}^{2+}+4 \mathrm{OH}^{-}+1 / 2 \mathrm{O}_{2}+\mathrm{H}_{2} \mathrm{O} \rightarrow 2 \mathrm{Fe}(\mathrm{OH})_{3}$

From the experimental results and according to the above reactions, it can be said that DO is the most significant parameter in the corrosion rate of steel. It was even reported that internal corrosion of water pipes can be prevented by reducing DO concentrations [21]. Liquid corrosivity is not only a function of dissolved oxygen but is also influenced by other factors. These factors include the conductivity of the water, dissolved solids, and the degree of acidity of the solution. The results of the conductivity and TDS measurements of the condensate fluids at various exposure times have decreased values as shown in Figures 6 and 7. Those results show that the liquid corrosivity of the condensate has changed as evidenced by the results of the corrosion rate in the first week (A1) and one last week (B). Theoretically, the corrosion rate of steel in water with high conductivity tends to be greater than in water with low conductivity [24]

\section{Condensate Quality Parameters}

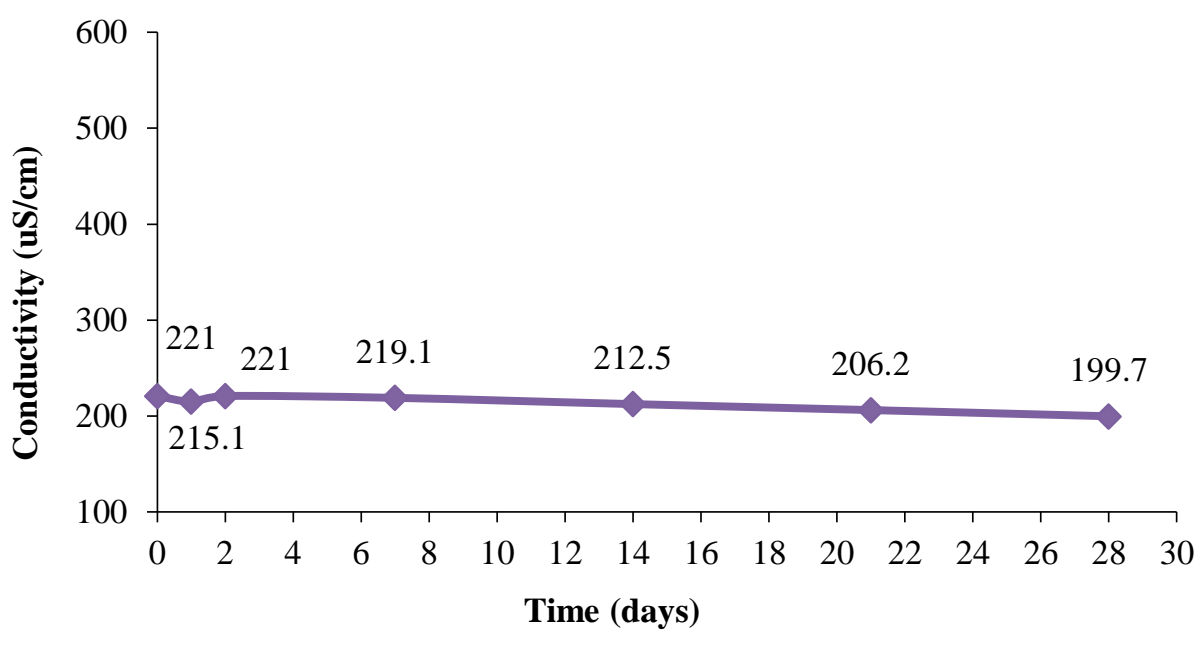

Figure 6 The result of conductivity versus exposure time.

Although the conductivity and TDS both have decreased, the decrease is relatively small so that it has no significant effect on the corrosion rate. However, theoretical total dissolved solids and high conductivity can increase corrosion rates [25]. This relates to the conductivity of the exchange of ions at the cathode and the anode more so that the rate of mass transfer of ions is faster [26]. 


\section{Condensate Quality Parameters}

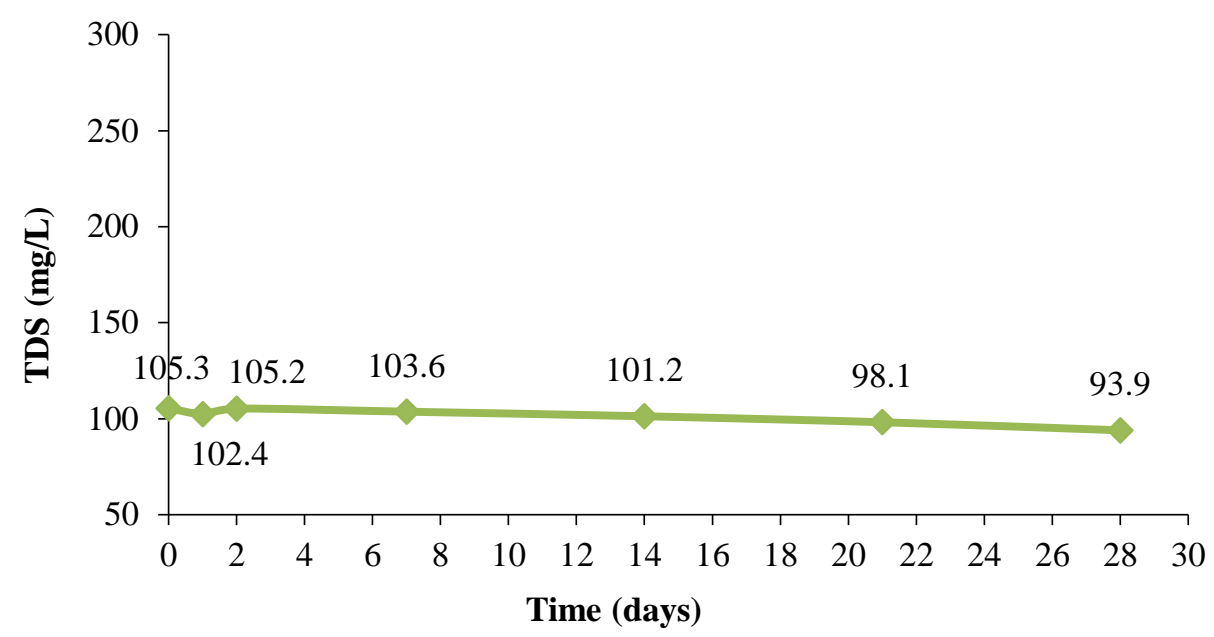

Figure 7 The result of TDS versus exposure time.

The measurement results of $\mathrm{pH}$ versus time are presented in Figure 8. These results show that an increase in $\mathrm{pH}$ after exposure and then the $\mathrm{pH}$ gradually decreases slowly. The measured $\mathrm{pH}$ after exposure is between 7.65 and 8.06. Based on the results of this $\mathrm{pH}$ measurement, the condensate fluid is categorized in a neutral environment that has little influence on the corrosion rate. However, a decrease in $\mathrm{pH}$ can make water more acidic and consequently the solution becomes more corrosive [9]. The effect of $\mathrm{pH}$ on the solubility of corrosion products during the corrosion process is often the key to understanding metal concentrations in the water environment [3].

\section{Condensate Quality Parameters}

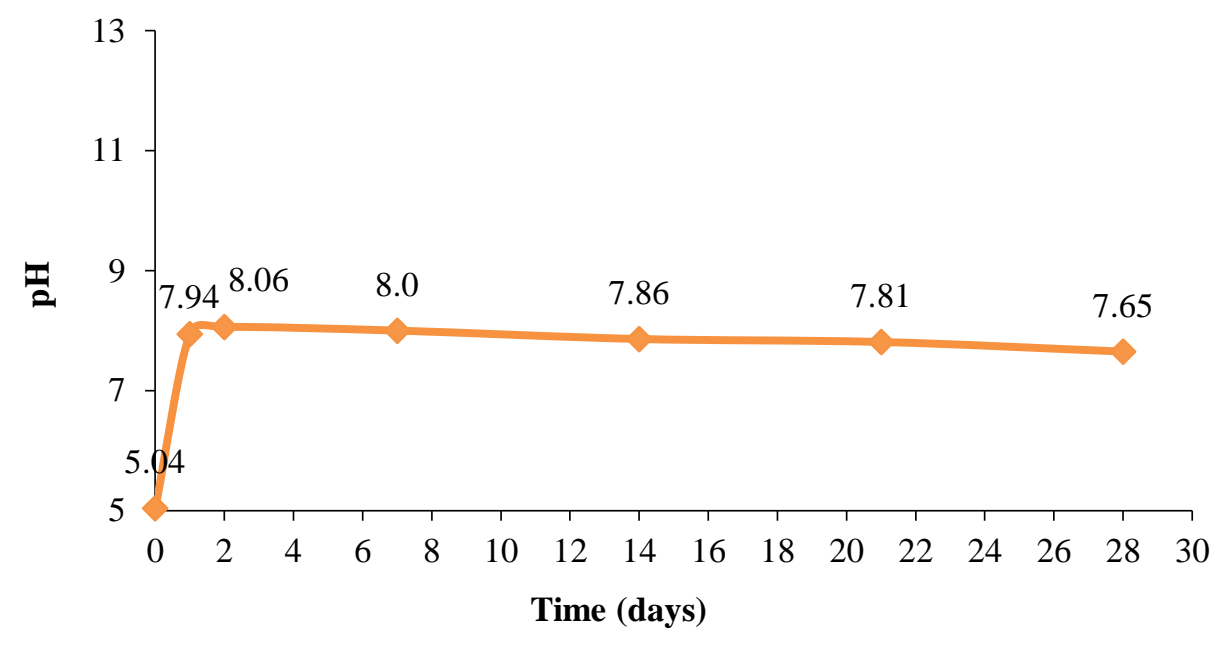

Figure 8 The result of $\mathrm{pH}$ versus exposure time.

The water quality parameters of the solution not only affected liquid corrosivity but also the corrosion rate of the metal. However, these parameters also affect the characteristics and morphology of corrosion products.

The visual and morphology of the corrosion products from low carbon steel pipe specimens are shown in Figure 9 with EDS in Figure 10. Carbon steel is very easy to react with dissolved oxygen in the 
water. The result of the corrosion reaction is iron oxide hydrate as a corrosion product. From Figure 9, it can see the morphology and the forms of corrosion, its uniform corrosion.

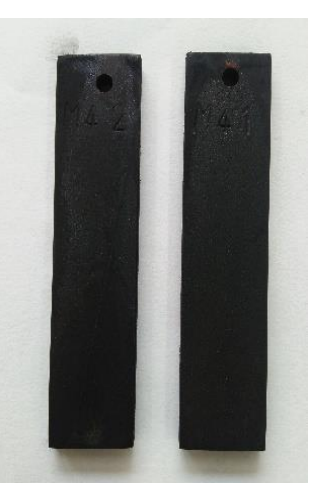

(a) Visual

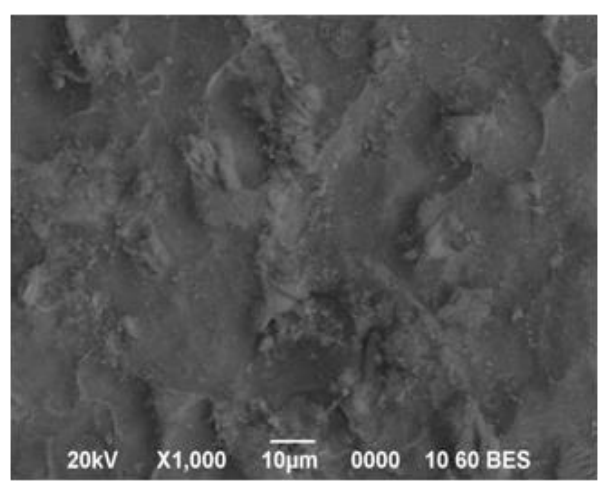

(b) corrosion product on the surface metal

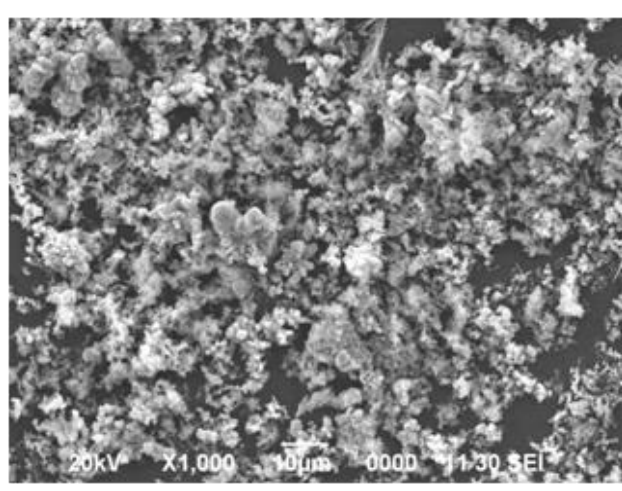

(c) Deposit of corrosion product

Figure 9 The visual and morphology of corrosion products for low carbon steel pipe.

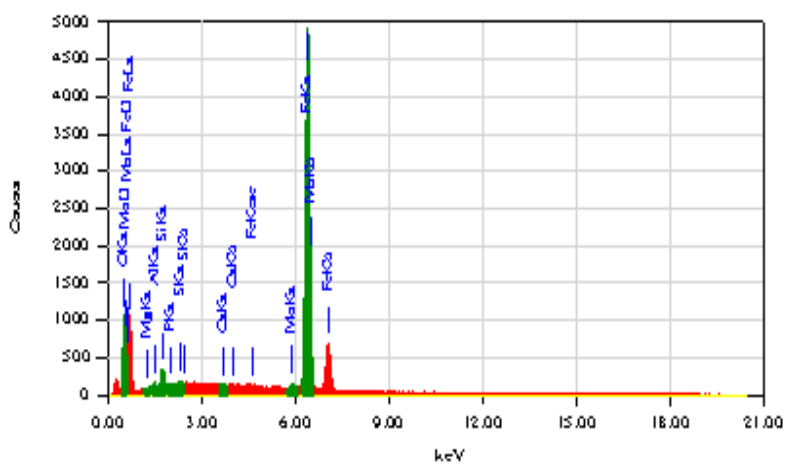

(a) Corrosion product on the surface metal

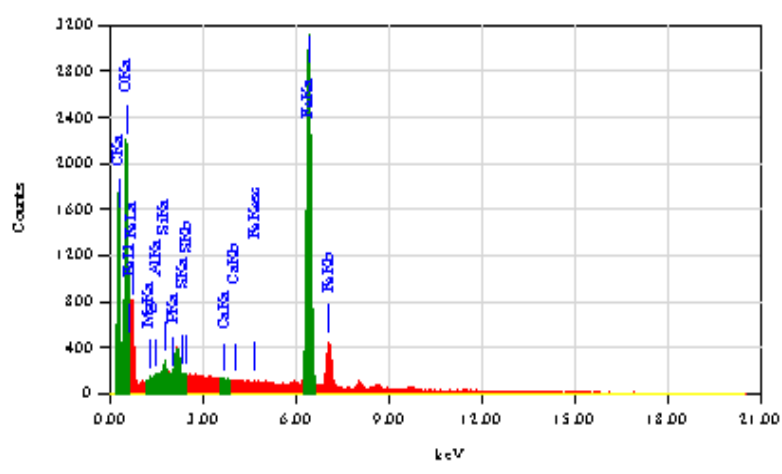

(b) Deposit of corrosion product

Figure 10 The results of the EDS for corrosion product.

The results of SEM and EDS indicate qualitatively to the dominant elements in corrosion products are iron, carbon, and oxygen. The content of the chemical composition of corrosion products in Table 6. The corrosion product on the metal surface, the carbon is not detected because the carbon content in the steel specimens is very low. While the carbon in the corrosion product on deposit was detected very high due to the use of carbon tape in the SEM test. Furthermore, the content of the element of S and P are minor elements, so they are not detected in the deposit of corrosion products. The distribution of rust products covered all surfaces metal as shown in the result of SEM photos in Figure 9.

Table 6 Element in corrosion product.

\begin{tabular}{ccccccc}
\hline \multirow{2}{*}{ Sample } & \multicolumn{7}{c}{ Element (\% Wt.) } \\
\cline { 2 - 7 } & Fe & O & C & Si & S & P \\
\hline Surface & 90.38 & 6.58 & - & 1.14 & 0.27 & 0.01 \\
Deposite & 51.08 & 20.57 & 27.90 & 0.34 & - & - \\
\hline
\end{tabular}


The results of surface morphology and elemental content of the corrosion product have not to predict the corrosion product compound. Therefore, an analysis by using x-ray diffraction was carried out to determine the corrosion product compound. The results of XRD on corrosion products are shown in Figure 11.

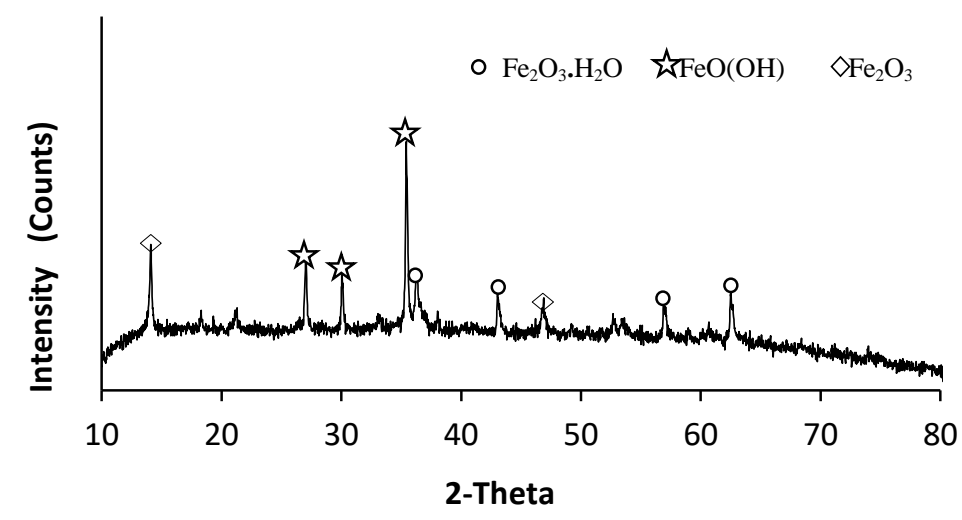

Figure 11 X-ray diffraction pattern for corrosion product.

The x-ray diffraction results of the experiment were matched with standard data diffractograms. The resulting matching obtained the oxides on the surface on carbon steel pipe are in the form $\mathrm{FeO}(\mathrm{OH})$ and $\mathrm{Fe}_{2} \mathrm{O}_{3} \cdot \mathrm{H}_{2} \mathrm{O}$. The result of corrosion products in the condensate environment are similar to studies of corrosion products in water environments [27-30]

\section{Conclusions}

In the immersion test of low carbon steel pipe in the condensate fluids, the liquid corrosivity of the condensate fluids tends to decreases during the immersion period with change water quality parameters. Meanwhile, the corrodibility of low carbon steel pipe decreases with the length of exposure time in this condensate media. The decrease of metal corrodibility is identical to the lower corrosion rate at a longer exposure time due to the layer a corrosion product formed. The corrosion products during immersion tests are uniform with iron oxide in the form of $\mathrm{FeO}(\mathrm{OH})$ and $\mathrm{Fe}_{2} \mathrm{O}_{3} \cdot \mathrm{H}_{2} \mathrm{O}$.

\section{Acknowledgments}

The author would like to thank the Research Center for Metallurgy and Material - Indonesian Institute of Sciences for corrosion laboratory support.

\section{References}

[1] AK Sinha. Aspects of failure of condenser tubes and their remedial measures at power plants. $A K S$ J. 2010; 1, 1-20.

[2] YM Al Rawahi, F Shaik and LN Rao. Studies on scale deposition in oil industries \& their control. Int. J. Innov. Res. Sci. Tech. 2017; 3, 152-67.

[3] FD Owa. Water pollution: Sources, effects, control and management. Mediterr. J. Soc. Sci. 2013; 4, 65-8.

[4] PR Roberge. Corrosion engineering: Principles and practice. McGraw Hill, New York, 2008.

[5] JF Kreider. Environmental engineering. In: DY Goswami (Ed.). The CRC handbook of mechanical engineering. $2^{\text {nd }}$ ed. CRC Press, New York, 2005, p. 161-7.

[6] S Prifiharni, A Royani, J Triwardono, G Priyotomo and Sundjono. Corrosion rate of low carbon steel in simulated feed water for heat exchanger in ammonia plant. AIP Conf. Proc. 2020; 2232, 020007.

[7] W Zhao, T Zhang, Y Wang, J Qiao and Z Wang. Corrosion failure mechanism of associated gas transmission pipeline. Materials (Basel) 2018; 11, 1935. 
[8] Y Chen, L Zhang, $\mathrm{H}$ Qin, L Xu and M Lu. Effects of temperature on $\mathrm{CO}_{2}$ top of line corrosion of pipeline steel. Corrosion 2011, Houston, Texas, 2011.

[9] $\mathrm{H} \mathrm{Li}, \mathrm{A}$ Shi, M Li and X Zhang. Effect of $\mathrm{pH}$, temperature, dissolved oxygen, and flow rate of overlying water on heavy metals release from storm sewer sediments. J. Chem. 2013; 2013, 434012.

[10] ER Alley. Water quality control handbook. $2^{\text {nd }}$ ed. McGraw Hill, New York, 2007.

[11] ASTM International. Standard practice for laboratory immersion corrosion testing of metals. ASTM International, Pennsylvania, 1985, p. 534-44.

[12] ASTM International. Standard practice for preparing, cleaning, and evaluating corrosion test. ASTM International, Pennsylvania, 1999.

[13] A Royani, S Prifiharni, L Nuraini, G Priyotomo, Sundjono, I Purawiardi and H Gunawan. Corrosion of carbon steel after exposure in the river of Sukabumi, West Java. IOP Conf. Ser. Mater. Sci. Eng. 2019; 541, 012031.

[14] MG Fontana. Corrosion engineering. $3^{\text {rd }}$ ed. McGraw Hill, Singapore, 1987.

[15] D Dwivedi, K Lepková and T Becker. Carbon steel corrosion: A review of key surface properties and characterization methods. RSC Adv. 2017; 7, 4580-610.

[16] SD Cramer and BS Covino. ASM handbook vol. 13c: Corrosion: Environments and industries. ASM International, Ohio, 2006.

[17] A Šalić and B Zelić. Introduction to environmental engineering. Phys. Sci. Rev. 2018; 3, 1-10.

[18] RW Revie and HH Uhlig. Corrosion and corrosion control: An introduction to corrosion science and engineering. $4^{\text {th }}$ ed. John Wiley \& Sons, New Jersey, 2008.

[19] Y Qi, H Luo, S Zheng, C Chen, Z Lv and M Xiong. Effect of temperature on the corrosion behavior of carbon steel in hydrogen sulphide environments. Int. J. Electrochem. Sci. 2014; 9, 2101-12.

[20] JL Wang, XM Zhan, YC Feng and Y Qian. Effect of salinity variations on the performance of activated sludge system. Biomed. Environ. Sci. 2005; 18, 5-8.

[21] N Sridhar. Effects of water and gas compositions on the internal corrosion of gas pipelinesmodeling and experimental studies. Corrosion 2001; 57, 221-35.

[22] S Wang, D Liu, N Du, Q Zhao, S Liu and J Xiao. Relationship between dissolved oxygen and corrosion characterization of X80 steel in acidic soil simulated solution. Int. J. Electrochem. Sci. 2014; 10, 4393-404.

[23] BR Linter and GT Burstein. Reactions of pipeline steels in carbon dioxide solutions. Corrosion Sci. 1999; 41, 117-39.

[24] A Royani, L Nuraini, S Prifiharni and G Priyotomo. Corrosion rate of various carbon steels in raw water for water cooling system at ammonia plant. Int. J. Eng. Trends Tech. 2018; 59, 51-8.

[25] Q Cui, S Chandra and S McCahan. The effect of dissolving gases or solids in water droplets boiling on a hot surface. J. Heat Transfer 2001; 123, 719-28.

[26] A Sander, B Berghult, AE Broo, EL Johansson and T Hedberg. Iron corrosion in drinking water distribution systems - the effect of $\mathrm{pH}$, calcium and hydrogen carbonate. Corrosion Sci. 1996; 38, 443-55.

[27] A Royani, S Prifiharni, G Priyotomo and Sundjono. Corrodibility of low carbon steel in immersion test using cooling water synthesis. Int. J. Mechatronics Appl. Mech. 2020; 2, 158-64.

[28] A Royani, S Prifiharni, G Priyotomo, J Triwardono and Sundjono. Corrosion of carbon steel in synthetic freshwater for water distribution systems. IOP Conf. Ser. Earth Environ. Sci. 2019; 399, 012089.

[29] N Tavanpour, M Noshadi and N Tavanpour. scale formation and corrosion of drinking water pipes: A case study of drinking water distribution system of Shiraz City. Mod. Appl. Sci. 2016; 10, 166-77.

[30] C Miranda-Herrera, I Sauceda, J González-Sánchez and N Acuña. Corrosion degradation of pipeline carbon steels subjected to geothermal plant conditions. Anti-Corrosion Meth. Mater. 2010; 57, $167-$ 72 . 